\title{
DESARROLLO SEXUAL PRECOZ
}

\author{
Por los Dres. ANTONIO MATTAR, OSCAR CORREA \\ y CARLOS URRUTIA.
}

Con el nombre de pubertad precoz se derigna un cuadro clínico-patológico caracterizado por la aparición precoz de signos y síntomas de maduración gentital y somática. Antes de plantear este diagnóstico, conviene tener presente el amplio margen de edad en que normalmente la pubertad se establece, lo cual parece depender de factores raciales y aun familiares. Así, resulta discutible, en muchos casos, hablar de pubertad precoz en paciente de 10 y 11 años, no así en los menores de 8. límite por debajo del cual hay acuerdo de la mayoría de los autores en considerar el desarrollo de los signos y síntomas propios de este estado como francamente patológico.

\section{Etiopatogenia.}

- Alteraciones de numerosas glándulas de secreción interna pueden ser causa de desarrollo sexual precoz. Entre éstas se deben mencionar la pineal, las cápsulas suprarenales, la hipófisis y los testículos y ovarios. Se describen también tipos no endocrinos de este cuadro, entre los cuales figuran el cerebral y el idiopático o constitucional.

Vamos a considerar, en primer lugar, la etiolc gía pineal. Tanto el carácter de la lesión pineal como su mecanismo de acción es todavía, a pesar de extensas discusiones, materia de gran controversia. Una de las numerosas teorías basada en estudios experimentales, supone como causa la ausencia de 
función de la glándula. Según Marburg y Goldzieher, sostenedores de este punto de vista, la secreción de la pineal actuaría como antagonista fisiológico de las hormonas que producen la maduración. En opcsición a esta hipótesis se halla la opinión de otros investigadores, quienes defienden como origen del cuadro una patogenia diametralmente opuesta, es decir, que él sería consecutivo a una hiperfunción pineal. Apoyan sus afirmaciones en estudios experimentales de Rowntree, autor que consiguió producir estados de pubertad precoz mediante la inyección de extractos de glándula pineal.

Se ha sostenido también que teratomas pineales sean la causa del sindrome. Estos tumores, que con cierta frecuencia se encuentran en este tipo de pacientes. producirian hormonas capaces de estimular el crecimiento. Existe, por último, otra teoría, defendida por Le Marquand y Russell, según la cual la bipófisis actuaría en forma directa en la producción del cuadro. Para estos autores, el mecanismo de acción seríz el desarrollo de hiperpituitarismo, estado en relación con tu. mores de la pineal. los que conducirían a este resultado ya directamente, debido al aumento de la presión intracraneana o por estimulación del hipotálamo. Al igual que las anteriores, esta tecría tampoco está exenta de importantes críticas $y$, en efecto, deja sin respuesta numerosas preguntas. Entre éstas se incluye la extraordinaria rareza de desarrollo sexual precoz en caso de procesos de hidrocéfalo interno, sea cual fuere la eticlogía de éste, que no es infrecuente, así como el hecho de presentarse el cuadro casi exclusivamente en varones.

De los tumores pineales capaces de acompañarse de sín- tomas clínicos, los principales son los teratomas, siguen en crden de frecuencia los tumores pineales específicos, luego los sarcomas $y$, por último, los melanomas. Entre las neoformaciones específicas se distinguen varios tipos, según su constitución. Los pinèalomas, por ejemplo, están formados por grandes células esféricas de núcleo vesicular, los pinealocitomas, por células más pequeñas y, en cuanto a la última variedad, llamados pineablastomas, se caracterizan por ser menos diferenciados que los anteriores. a la vez que presentar crecimiento maligno.

Otro origen probable del cuadro de desarrollo sexual precoz es el córticosuprarenal. Si bien se puede presentar en ambos sexos, es más frecuente en la mujer. La sintomatologia, aunque ajustada en líneas generales a ciertas características, varía con la naturaleza histológica de la lesión. Así, 
mientras en casos de hiperplasia o adenoma de la corteza, los signos de maduración sexual presentan un lento desarrollo con constitución en la mayor parte de los casos de marcada obesidad, en pacientes con tumor maligno el cuadro clínico se establece en forma más o menos rápida, sin alcanzar a observarse, en muchos de ellos, grados acentuados de obesidad.

De las numerosas neoformaciones que pueden desarrollarse en la corteza suprarenal, las de carácter nodular son las más frecuentes $\mathrm{y}$ corresponden, como sucede en la mavor parte de los casos, a adenomas verdaderos. Estos, a menudo bilaterales. varían en tamaño entre el de una arveja al de un huevo de gallina y su estructura es, pór lo general, trabecular. En la corteza pueden también 'crecer tumcres malignos, de cbservación más rara que los anteriores. Ellos se caracterizan por su rápida extensión y la precocidad con que dan lugar a metástasis y en la mayor parte de los casos se desarrollan a partir de tejido propic de la corteza y únicamente por excepción de tejido interrenal accesorio.

Debemos considerar, en seguida, entre las probables eticlogías del cuadro en estudio, alteraciones de la hipófisis. Contrariamente a lo esperado. la participación que a esta glándula le cabe en tal sentido, es escasa y aun muchos niegan la existencia de cuadros de este origen. Fuera de algunos casos de macrogenitosomia y establecimiento precoz de la pubertad en relación con gigantismo, síndromes probados de pubettad precoz de etiología hipofisiaria son extraordinariamente ratos.

En cuanto al carácter de las alteraciones hipofisiarias on casos de pubertad precoz, debides a este origen, no existe aún, debido a la escasez de datos anátomopatológicos, un conocimiento claro. A este respecto, sólo es posible decir que si bien tanto en conexión con adenomas fosinófilos como basófiles se ba descrito la aparición de estados de pubertad precoz, Ia ausencia en otros casos de tales lesiones hacen difícil establecer la naturaleza oxacta de los cambios glandalares que llevatían a la producción excesiva de hormonas gonadotrópicas.

Cuadros de desarrcllo sexual precoz pueden, también, como ya se dijo, tener su origen en las gonadas, testículos a ovarios. Esta última posibilidad, con mucho la más frecuente, se debe. por lo general, al desarrollo de un tumor de células granulosas, cuya principal característica la constituye su propiedad de secretar estrógenos, cuyos efectos son, en las niñas, el desarrollo sexual preccz y, en la mujer adulta, la hiperplasia quística del endometrio. Si bien se trata, general- 
mente, de un tumcr benigno, en algunos casos, cuya frecuencia fluctúa de 10 a 30 por ciento, puede éste adquirur malignidad. Microscópicamente se caracteriza por estar constituido por células pequeñas, con escaso citoplasma, el que muestra escasa diferenciación. Las células aparecen a menudo agrupadas alrededor de finos lúmenes, aspecto que simula cavidades foliculares primitivas: Desde el punte de vista macros. cópico, el tumor puede ser sólido o quístico y se particulari za por su facilidad a desarrollar necrosis. Si bien es frecuente que sea unilateral, puede también encontrarse en ambas glándulas.

Al lado del tumor de células granulosas pueden tambien los oyarios ser asiento de cambios que conducen al estado designado con el nombre de ovarios poliquísticos, igualmente de importancia en relación con el cuadro en estudio. A pesar de que es hallazgo normal encontrar en la autopsia pequeños quistes ováricos, la presencia de un número excesivo de ellos ha de considerarse patológica. La naturaleza de los quistes es variada y así, al lado de formaciones foliculiares, se describen otras constituídas por células luteínicas y granulosas. Estas últimas, que como las anteriores, serían el resultado de una estimulación ovárica anormal, por un exceso de hormonas gonadotrópicas del lóbulo anterior de la hipófisis. tendrían la capacidad de producir estrógenos y en esta forma dar origen a estados de pubertad precoz (Goldzieher).

En cuanto al origen testicular del cuadro, debemos decir que es ura posibilidad muy rara, La maduración y función prematura de los testículos, en la mayoría de los casos se presenta como el resultado de alteraciones de otras glándulas. La naturaleza exocta del mecanismo de acción en tales circunstancias sería, o una estimulación excesiva de los testículos que los lleva a un estado de función comparable al que se produce al astablecerse fisiológicamente la pubertad o a un defecto de las glándulas alteradas para suministrar los factores de inhibición que normalmente retardan su maduración.

La naturaleza del tumor testicular capaz de desarrollar propiedades endocrinas es variada $y$, al efecto, se mencionan adenomas, carcinomas y teratomas, Los primeros son rares y pueden tener diferentes origenes, células de Sertoli, residuos de las rédecillas y células intersticiales. De éstos, los más fre cuentes parecen ser los derivados de las células intersticiales, que de preferencia aparecen en testículos ectópicos y que tal vez son los únicos cuyo rol endocrino no se discute. ya que el 
significado, en igual sentido de los otros, es dudose $y$, en efecto. $\mathrm{x} x \mathrm{t}$ te más bien tendencia a considerarlos como simples ancmalias del desarrcllo. Si bien los tumores de células intersticiales son de naturaleza reconocidamente benigna, se describen casos, muy raros, en que han adquirido creciniento invasor $\mathrm{y}$ dado, incluso, origen a metastasis. Respecto a los tarcinomas, ellos derivan de los túbulos seminíferos y son conocidos de preferencia con el nombre de seminomas. Pueden ser sólidos o quísticos, el primer típo, con mucho, el más frecuente, y se caracterizan por su sensibilidad a los rayos $X$. Los teratunas, como los tumores recién mencionados, pueden también ser sólidos o quísticos. Si bien estos últimos, que en ocasionei tienen elementos dermoides, son, por lo general. de carácter benigno; los primeros, así como los de estructura micrcquistica, frecuentemente se. comportan como mailignos. Entre los teratomas debe también ser incluído el corioepitelioma, tumor que se desarrolla de un teratoma benigno. $\mathrm{Di}$ cho tumor, como se sabe, es de gran malignidad y, al efecto. se caracteriza por su crecimiento rápido y la producción precoz. de metástasis.

Po: último, se debe, también considerar, como ya se dijo, al discutir las posibilidades etiológicas de un caso de desarrollo sexual precoz, su origen no endocrino, ya cerebral o constitucional. Lesiones cerebrales de diversos tipos, ence falitis, tumores (Ford y Guild, Eaves y Kroll, Schlessinger, etc.), procesos de hidrocéfalo interno, malformaciones de la región hipotalámica, etc., pueden, en realidad, acompañarse, en ocasiones, de la aparición de precocidad sexual. Como ciaramente lo expone Seckel en una revisión reciente de la materia, todas las causas antes señaladas, al igual que lesiones de la pineal e hipófisis, sobre cuyo mecanismo de acción, cono ya se dijo, hay gran controversia, llegarian a producir la sintomatología mencionada a través de una perturbación de las corexiones hipotalámicas hipofisiarias.

En cuanto a los cuadros de pubertad precoz de origen idiopático o constitucional se les relaciona a factores gencil$\cos$, que son los que determinarían el tiempo de maduración sexual. Si bien sólo en algunos pacientes es posible establecer cierta relación familiar, se piensa que en dichos sujates. por características especiales de su constitución, el o los centros del sexo. que se suponen situados en el hipotalamo, alcanzarian precozmente su completo desarrollo. 
Sintomatología y diagnóstico.

Si bien la sintomatología del cuadro de pubertad precoz es, en lineas generales, parecida en todos los casos, sea cual fuese su etiología, se describen signos variables según ésta. En caso de origen córticosuprarenal del síndrome, éste se caracteriza en los niños por aumento del panículo adiposo y masas musculares, esto último, en grado tal, que han conducido a algunos autores, en atención a la extraordinaria fuerza que demuestran tales niños, a designarlos con el nombre de "niños o lactantes Hércules". Hay, idemás, alimento del rene. en algunos ríños, muy acentuado, no así de los testículcs, los que sólo por excepción se presizntan de mayor tamaño que el correspondiente a la edad, junto a lo cual se aprecia désartollo piloso púbico y facial.

En cuanto a las niñas, en quienes, como antes se dijo, el cuadro alcanza una frecuencia más alta que en los niños. 1a cbesidad es también manifiesta, no asi el desarrollo de la musculatura y esqueleto, que sólo por excepción son considcrables. Como en el niño $y$, tal vez, en mayor grado qué en él, hay abundante desarrollo piloso, con aparición de ćste en la región púbica, axilas y cara. El cítoris se presenta aumentade de tamaño, en ocasiones, como un pequeño pent. Es importante hacer presente que a diferencia de cuadros de desarrollo sexual precoz que reconocen ctro origen, las niñas no presentan crecimiento anormal de las glándulas mamarias $\mathrm{ni}$ menstruación, lo que se explica. ya que el síndrome se dzbe a la produicción excesiva de hormonas androgénicas. Por las razones antedichas, el cuadro se describe más acortadamente con el nombre de pseudo pubertad precoz o de precocidad sexual incompleta, términos muy justificados, ya que en los niños no existiría esparmatogénesis ni en las niñas ovulación.

$E_{n}$ casos de origen gonadal, la sintomatología es de tipo iso-sexual para ambos sexos, a saber, aparición de menstruación, desarrollo marcado de los senos y clítoris de tamaño normal en las niñas y pene grande y voz gruesa en los niñ́cs. En ambos tipos de pacientes hay, naturalmente. aparición de vello púbico y axilar, más matcado én los niños, en quienes se observa también en la cara. Como en los casos de etiología córticosuprarenal, la precocidad genital es también incompleta.

Tanto en los cuadros de origen pineal como hipofisiaris y cerebral, la sintomatología es idéntica. Ella tiene las 


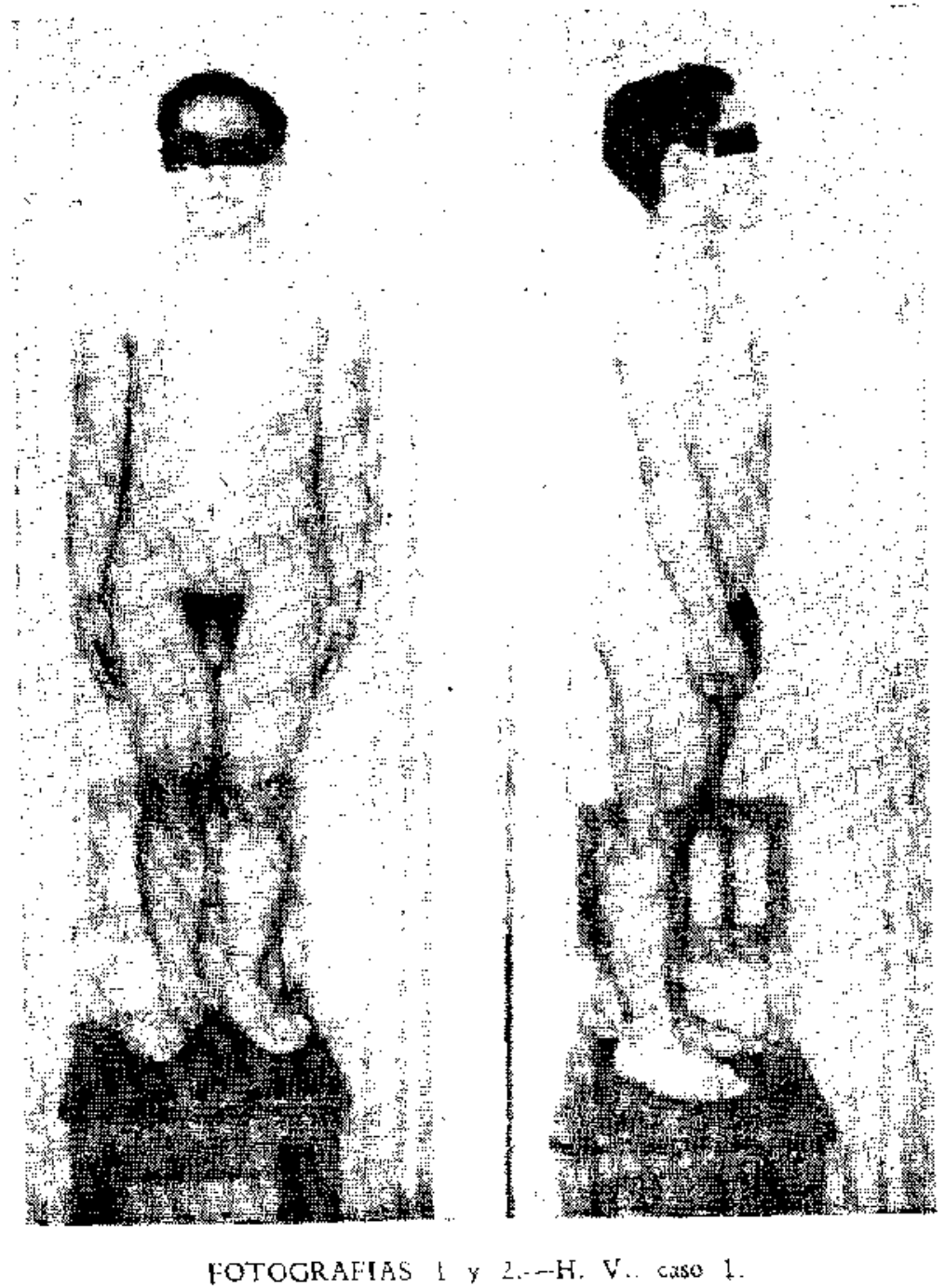




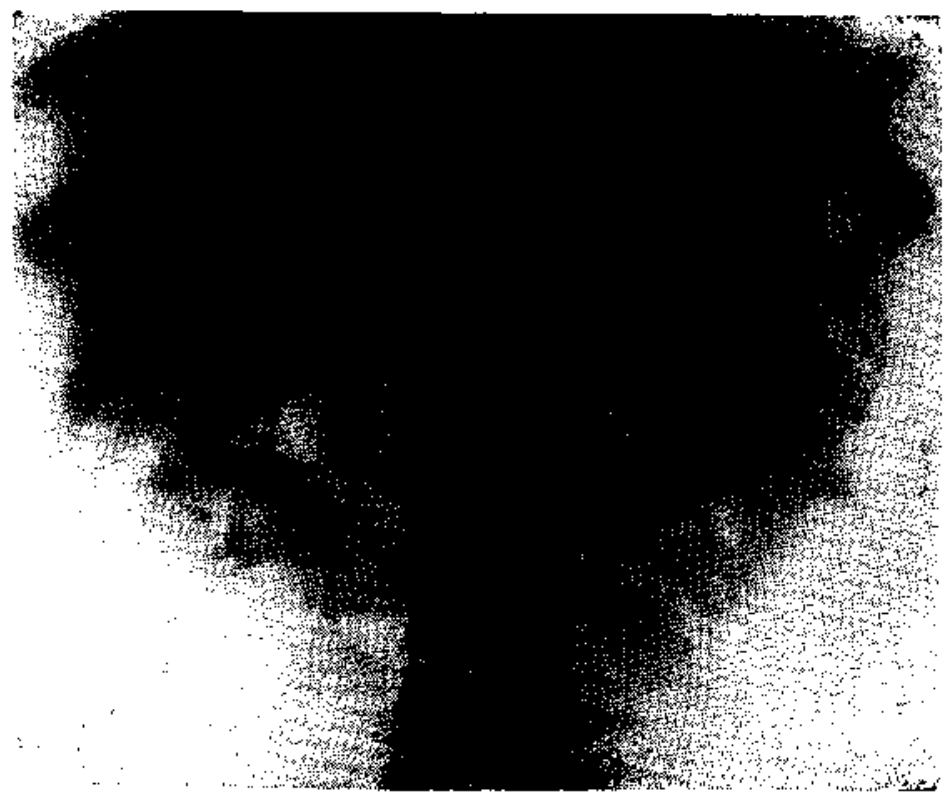

RAD. 1.

Nótese la marcada calcificación de los cartilagos costales (sólo observada normalmente en individuos di más de 60 años).
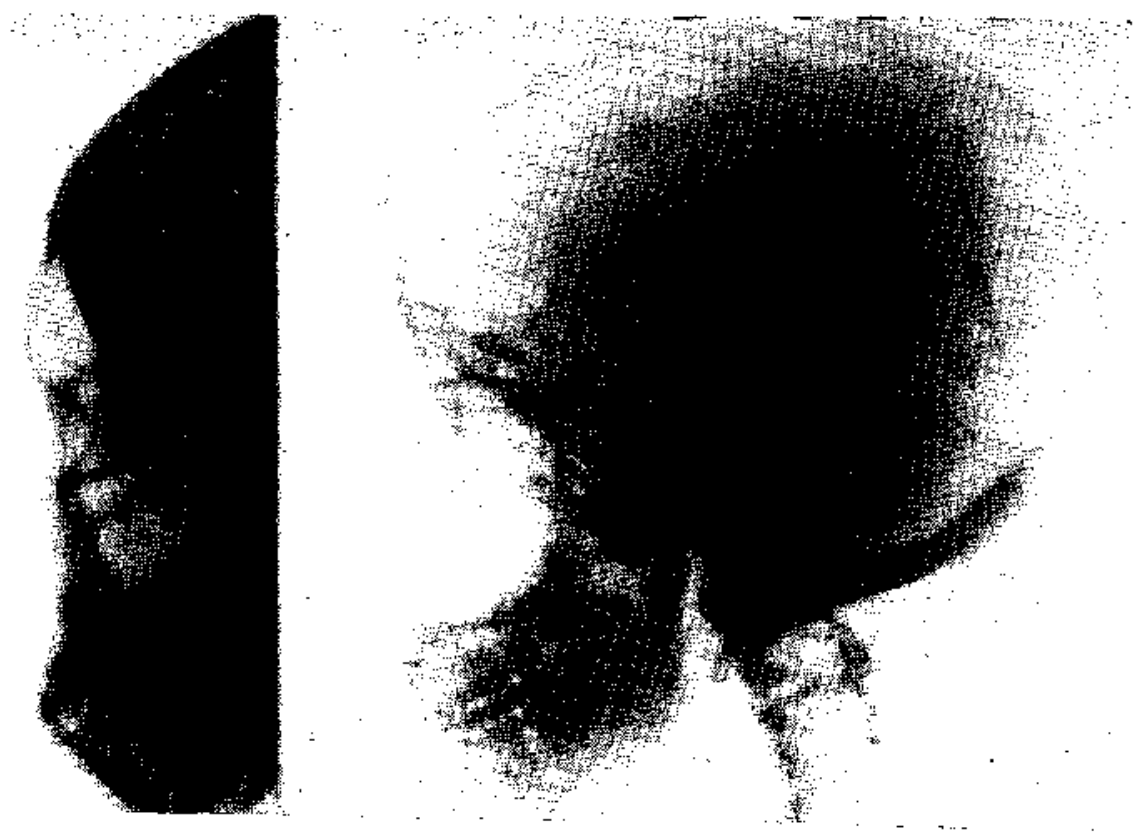

RAD. 2 .

Silţa turca normal, Matcado anmento de la neumatización. (Rad. 2b). 

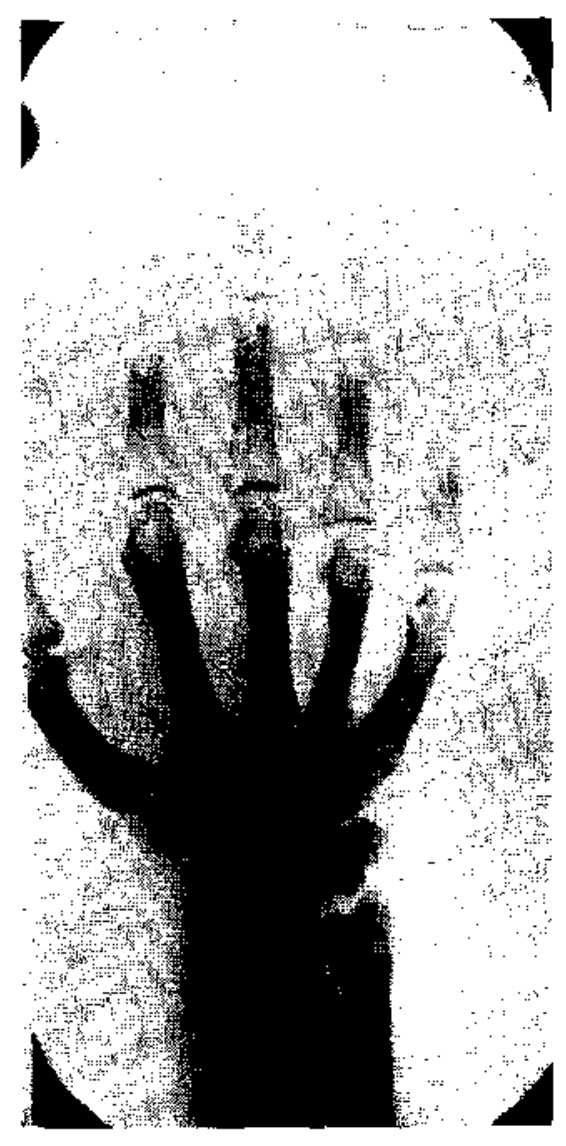

\section{RaD. 3.}

Avanzado estado de osificación dol carpo (udad ósca de 17 añes ctad cronológi: 11 a ins 9 meses). 


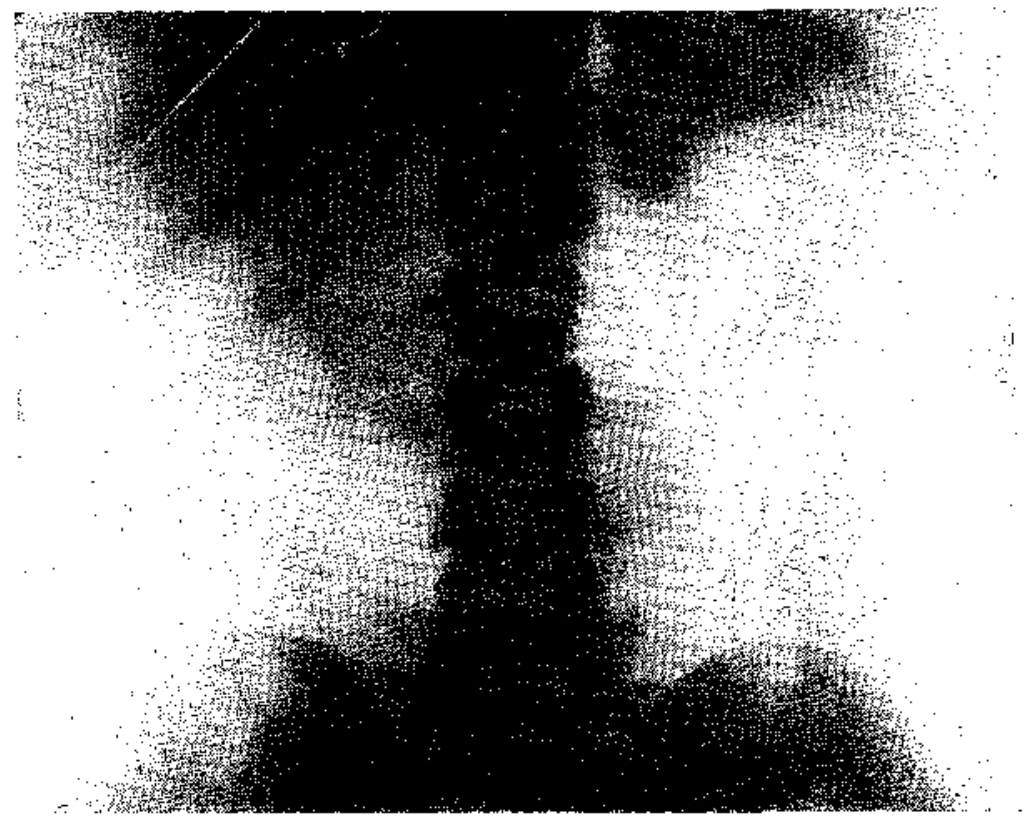

RAD. 4.

Panumoroentgenograma patireni. Obsétvase el gran aumento de ranuío de i.i capsula suptarenal izquierds (la inyección de aire a deracha se hizo 3 dias desputés de este examen!.

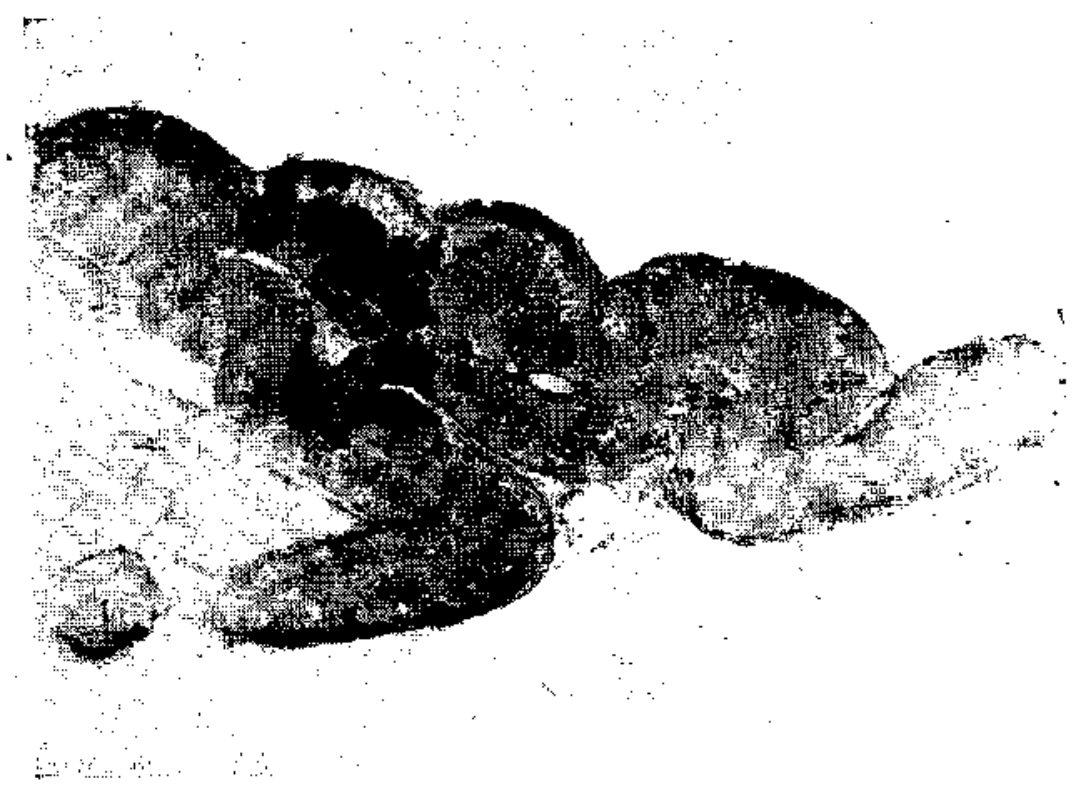

MLCROFOTOGRAFIA .

Vista panorámica de la suprarenal en corte transrersal. 


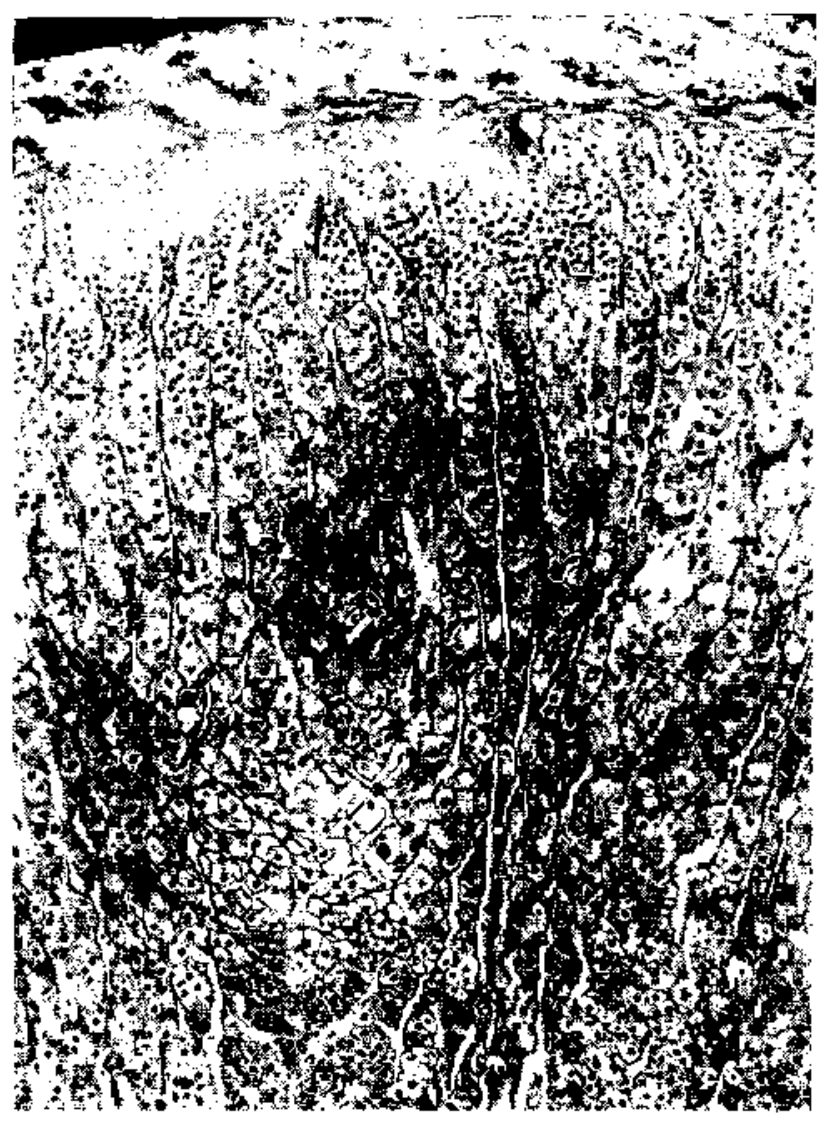

\section{MICROIOTCGRAFIA 2.}

Ccrie de la corlical visto ion aumenco mayor. Noțese la dispositjon notrala de

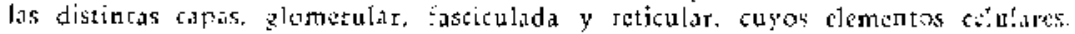
si binn sia alterationes en su forma ni tamaño. se presentan alumentados numéricamente.

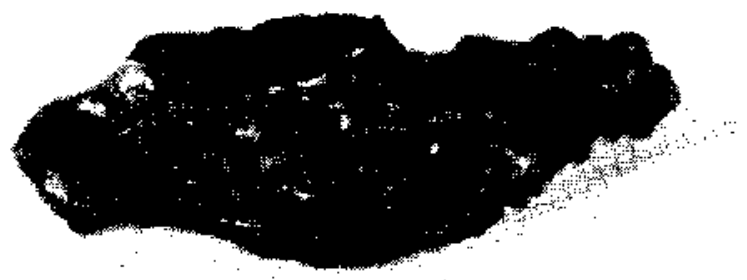

FOTOGRAFIA 3,-Cápsula sppratenal extirpada (peso lj grs.). 


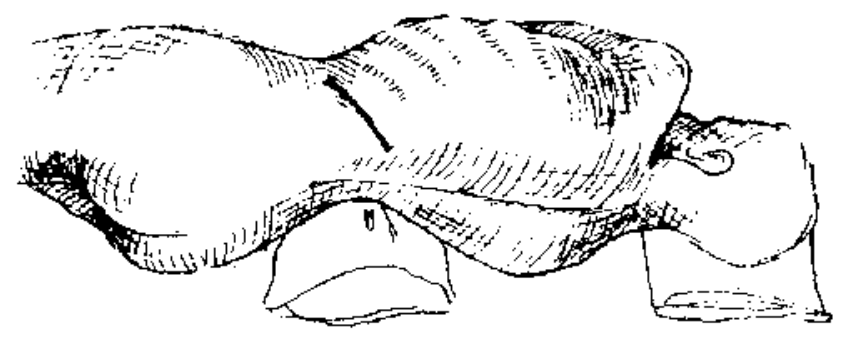

Fig. A

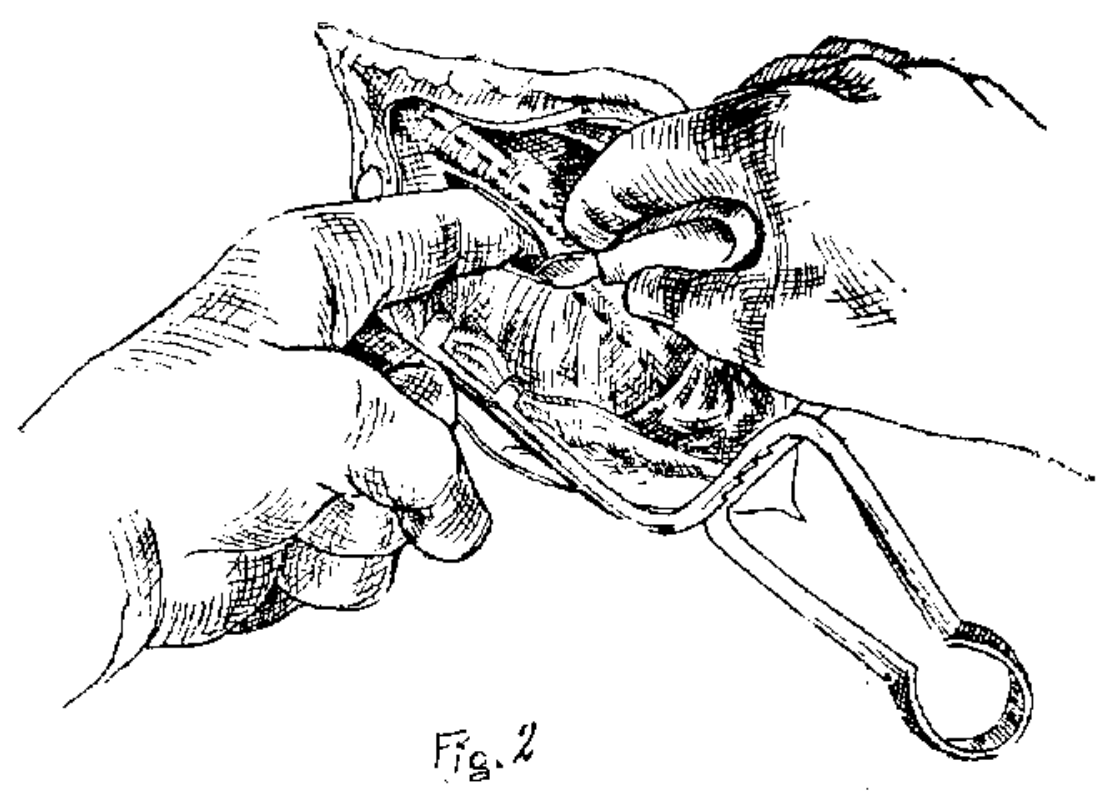

Representación esyuematica de Los cuatro ticmpos principales de la operación de Ineriz (ver texto). 

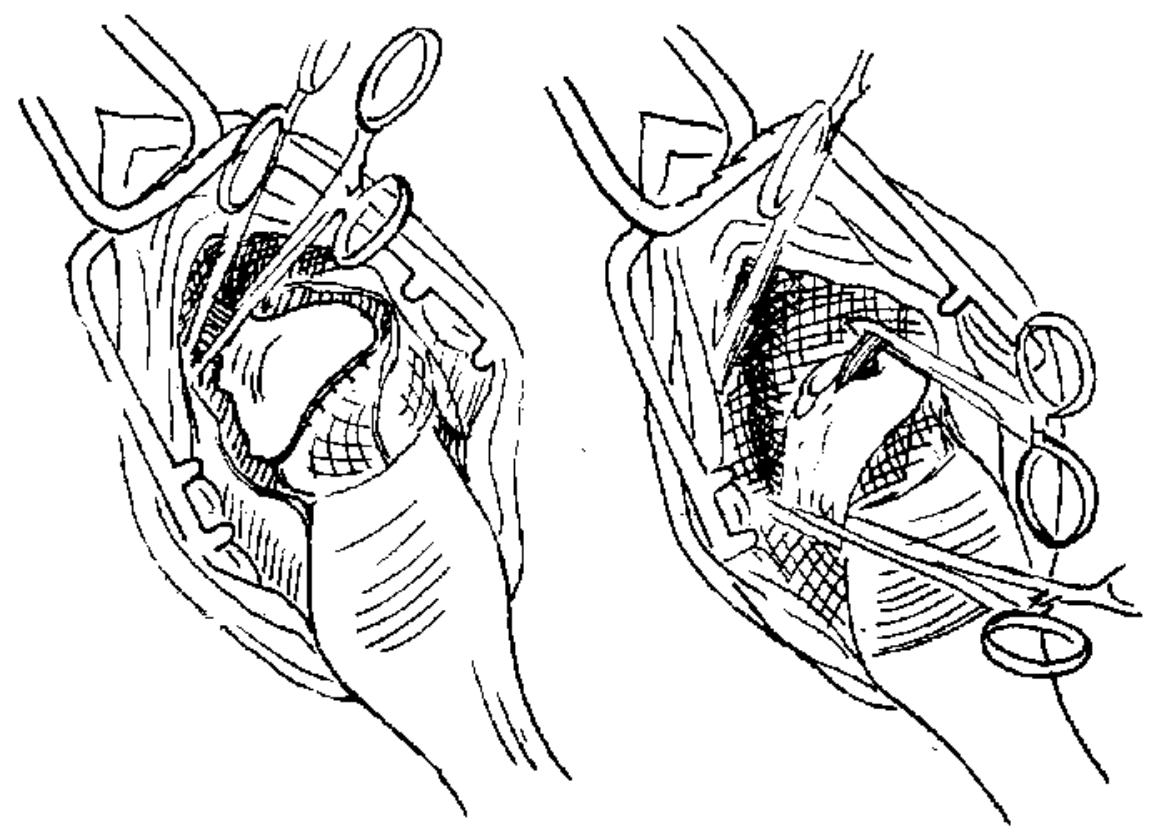

' $\varepsilon$ 'DIII

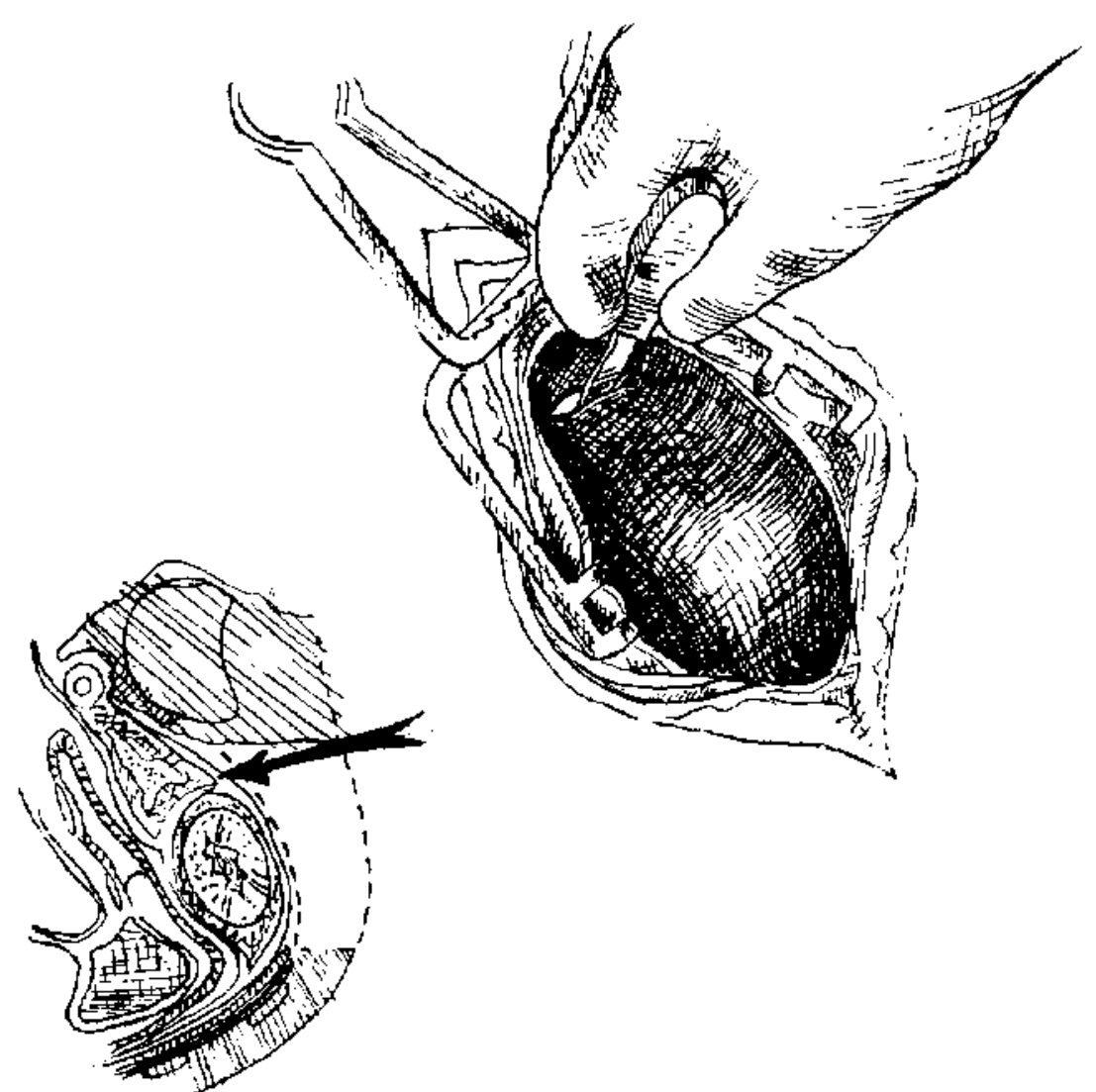




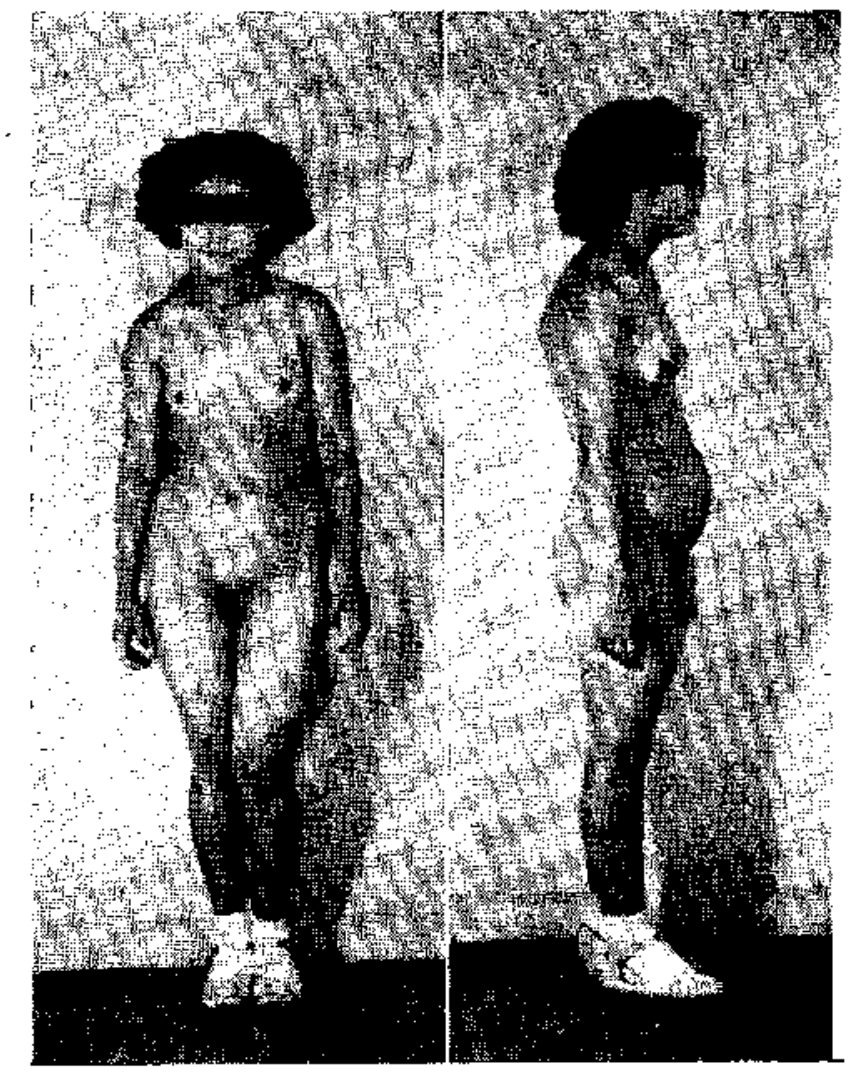

FOTCGRAFIAS 4 y 5.-C. M., caso 2 . 


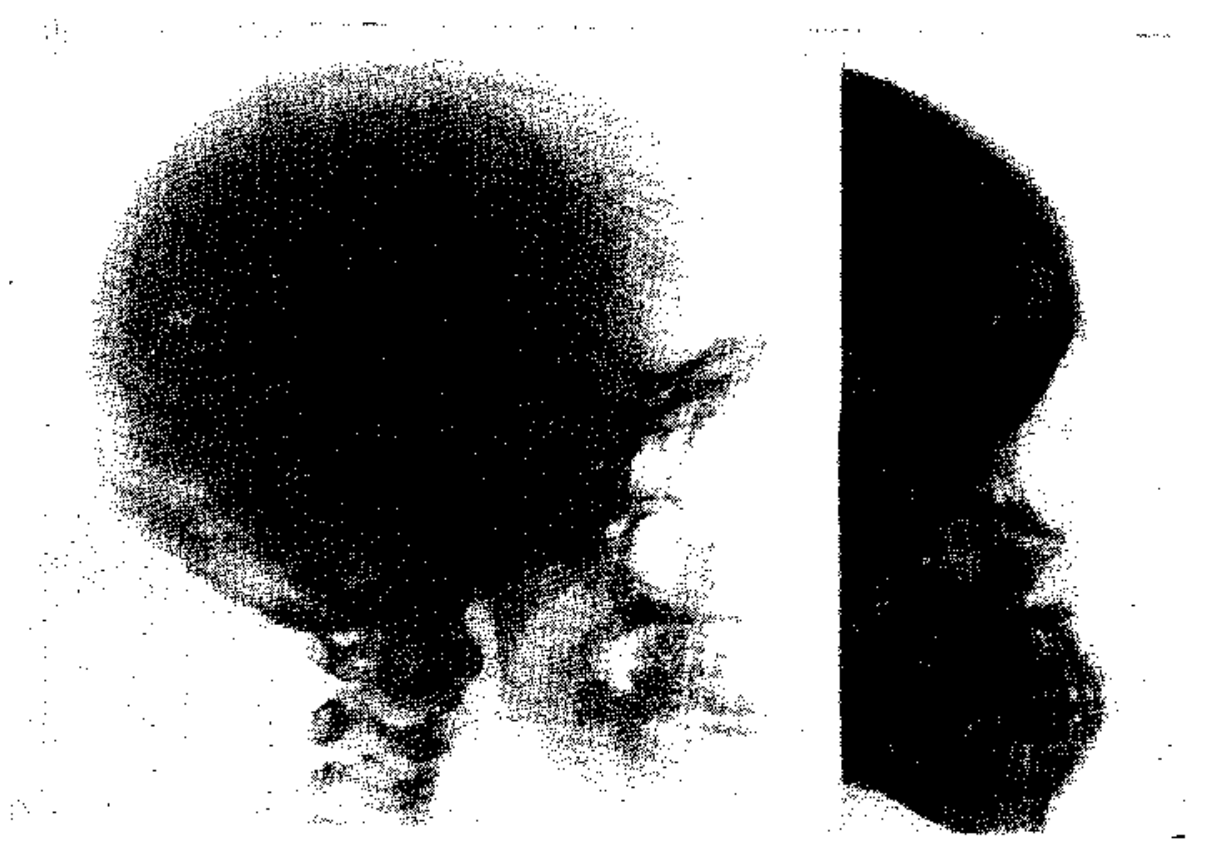

RND. 5.

Neumatización $y$ silla turea normales (la silla rueca deberia tener $1.2 \times 0.625$. tive $1.1 \times 0.7(3)$. 


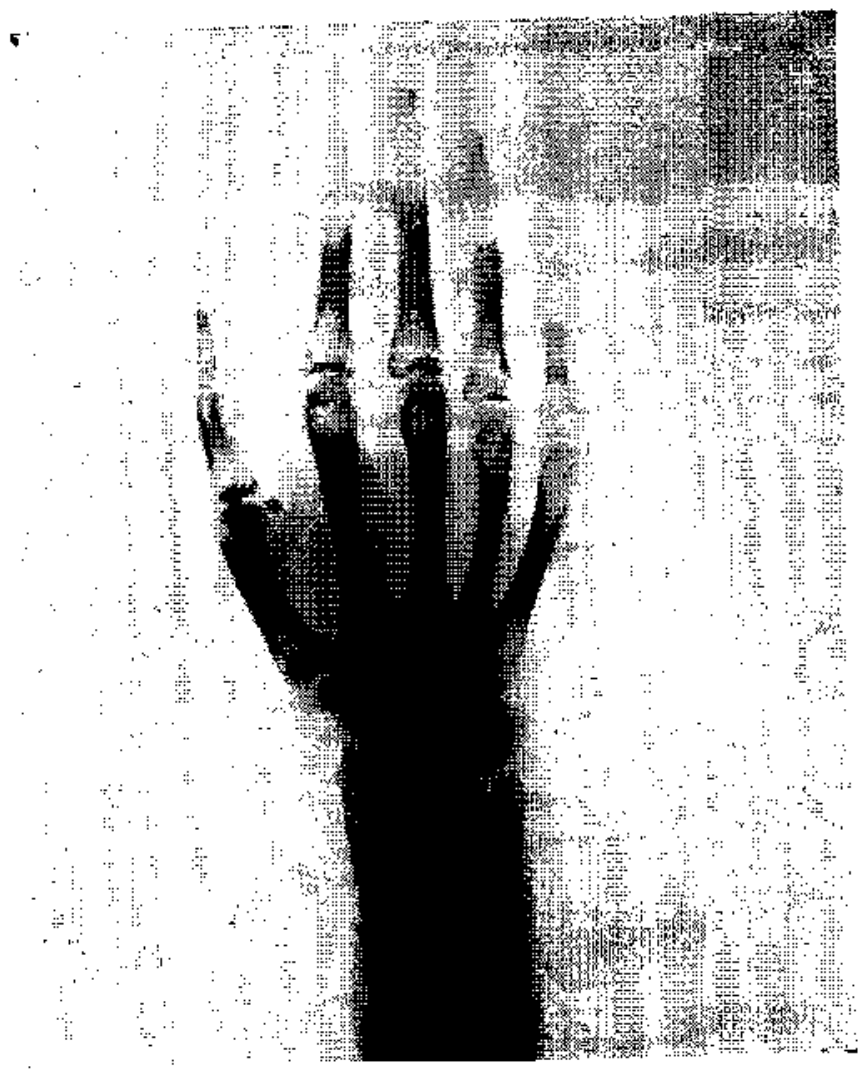

RAD. 6.

Edad ósea de 15 años (edacl cronológica de 10 años 9 neses). 
características de una precocidad isosexual completa, es decir, iguales signos que los descritos para el tipo gonadal, a los que se agregaría espermatogénesis en los niños y ovulación en las niñas. Está de más hacer presente que en pacien-i tes con pubertad precoz de origen constitucional o: idiopático, la sintomatologia es igual a la recién descrita.

Un punto sobre el cual conviene llamar la atención es la existencia en todos les casos de desarrollo sexual precoz, sea cual fuere su etiologia, de un crecimiento longitudinal excesivo en las primeras etapas del cuadro, el cual posteriormente, debido a la soldadura precoz de las líneas epifisiarias, cesa y da por resultado, cuando estos pacientes sobreviven, a una talla definitiva subnormal.

De la descripción sintomatológica que precede es evidente que el diagnóstico etiológico del cuadro de pubertad precoz no es fácil. En muchos casos éste sólo puede plan-1 tearse en el terreno de la probabilidad. Agotada la pista que en tal sentido proporciona la clinica, puede recurrirse a algunos exámenes complementarios, estudios radiográficos especiales (pneumoencefalograma, pneumoroentgenograma nerirenal), determinación de hormonas, etc., que en muchos casos son de gran utilidad. Si bien la naturaleza delicada de algunos de estos exámenes restringen el estudio dé este tipo de pacientes a servicios especializados, debemos decir que en muchos casos ellos son los únicos que permiten al clínico sentar con cierta seguridad el diagnóstico etiológico.

A continación nos permitimos relatar dos casos de desarrollo sexual precoz que nos ha tocado en suerte atender últimamente en el Hospital Luis Calvo Mackenna.

\section{CASO N" 1 .}

HUGO V. - Observación clínica: 45/2145. - Edad: 11 años 9 meses.

Enfermedad actual. - Es enviado (5.V-45) por el médico escolar (Dr. A. Aguileral, por presentar características morfológicas y funcionales especiales. Estas, que empezaron a hacerse manifiestas a los 8 años, consisten en crecimiento acenruado del pene. gran desarrallo de la musculatura, vello púbico $y$ axilar, voz de tonalidad de adulto y a menudo execciones y masturbacićn.

Antecedentes familiares. - Padres de 46 años, aparentemente sanos, sin anteccdentes Juéticos, tnberculosos ni alcobólicos, El es de talta baja, bien proporcionado. Dos hijos, el otro una niña de 17 años, sana. No ha babito 
abortos. No hay ni ha habido entre los miembros de la familia sujetos con alteraciones morfológicas, funcionales o priquicas.

Antecedentes personales. - Nació de embarazo de término, en paxto normal. Aunque no se pesó, se dice habar dado la impresión de ser us niño notmal a este respecto. Fué alimentado al pecho materno exclusivo hasta los seis reses. edad desde la cual empizó a recibir sopas, purés $y$ jugos de fritas. A partir de los 9 meies. mamaderas complementarias de lache de vaca. en cocimiento farinaceo. A los 6 meses aparición de los incisivos centrales inferiores, con frupción posterior regular de los dientes restantes. Sostuvo la cabeza a los 3 meses. se sentó a los 6 y se rontuvo de pie y dió los primeros pasos a los 9 y 11 meses, respectivamente. Ptimeras palabras a! año. Fuera de sarampión, bace 2 años, no ha puisentado enfermedades dignas de mentión.

Es un niño de carácter reposado. ranquilo. Tiene especial afición por los ejercicios de fuecza. Actualmente cursa quinto año de escuela primaria, Vive en una cité. Alimentación buena.

\section{Examen objetivo.}

Niño en posición activa, lúcido. Deambulación normal. Llama la atentión el matcado desarrollo de las masas musculares, que le dan el aspecto de an pequeño Hércules. Esto lis sobre todo evidente en las extremidades y torso. donde es posible observar claramente los relieves individuales de los músculos. Piel morena, sana. Parículo adiposo, escaso, regularmente distribuido. Disarrollo piloso púbico y axilar abundante, especialmente el primero. No bay hirsutismo. Se palpan pequeños ganglios 5ubmaxilates (fotografias 1 y 2 ).

Peso: $45.5 \mathrm{kgrs}$. Talla: $1.42 \mathrm{~m}$. Desviación por ciento del feso del stanclard de peso para talla $y$ edad: $+27 \%$. Circunfetencia del cráneo: $56 \mathrm{cms}$; circunferencia del tórax: $76 \mathrm{5m3.;} \mathrm{circunfensucia} \mathrm{del} \mathrm{abdomsa:} 70$ cms.: segmento superior: 73 cms.; segmento inferior: $69 \mathrm{cms}$. Y envergadura: $1.44 \mathrm{cms}$.

Pulso: 72: respiraciones: 14; temperctura: 36.5: presion sanguinea: $118 / 76$.

Cabeza. Cráneo: dolicocéfalo, simétrico: boca: dentadura completa, sana: ojos: reacciones a In luz y acomodación normales; visión: O. D. 5/7.50. O. I. $5 / 7.50$; fondo de ojo y campos visuales: nada de especial: cuella: cartílago laringeo prominenta: tórax: ancho, de paredes firmes (tạd, 1): marcada cal. cificación de los cartílagos costales, comparable sólo a la observada en indivi. duos de 60 a 70 años: gran excursión respiratoria: nesto y abdomen: examen negativo; riñones: no se palpan: no hay puntos dolorosos renoureterales: genitaies: pene de dosarrollo de adulto, de 8.5 cms. de longitud por 3 cms. de diánetro: testiculos de forma, tamaño y consistencia normales: êpidídino, cor dones y próstata: nada de especial: uretra: sin secreción. 
Con 'a sospecha. por el resultado del examen anterior y el fuerte desarro1lo $d_{2}$ la musculatura. de un hiperinterrenalismo, sz solicitan en polílinica varios exámenes y Iuego el niño se hospitaliza, a fin de permitir su estudia completo. A' continuación se indican los exámenes a que il niño fué sometido: Firquet: +; radioscopia de tórax: nozmal: Kahn-Kline $y$ orina: negativos: coleterolemia: 1 ge. por mil; glicemia: 1.05 Bt. por mil; hemograma: glóbulo: rojos: 4.660.000: glóbulos blancos: 10,900; hemoglobina: 16.2; basófios: 0 : eosinófilos: 1: mielocitos: 0 : juveniles: 1 ; bacilitormes: 18 ; segmeniados: 55: linfocitos: 16, y monocitos: 9: prueba de tolerincia a la glucosal $1.11,2.10,1.66,1.14 \mathrm{~V} l \mathrm{gr}$. por mil; creatinina y creatina en orina de 24 horas: 1,190 y $10 \mathrm{mg}$., respictivamente (coeficizntes de 27.8 y 0.2 $\mathrm{mg} / \mathrm{kg}$ ): metabolismo basal: $-6.5 \%$ : acción dinámica especifica de las proteinas: $+24 \%$; capacidad vital: $+30 \%(3.480 \mathrm{cc} .2 .66 \mathrm{cc}$. por m.2): radiografia de cráneo (rad. 2): silla turca de forma $y$ tamaito normal. aumento de la neumatización; radiografia de carpo (rad. 3): edad ósea de 17 años y 17 ketosteroides urinarios: $18.4 \mathrm{mg}$. de androstizrona en 24 horas.

El estudio del paciente se completô con examen neurológico. que tesultó nagaivivo. y exámenes psicológicos y psiquiátricos. Respecto a ústos últimos. dibemos decir. en obsequio a la brevedad, que el peinero reveió una edad mental de 13 años 6 meses (C. I.: 1121 . según el trst de Porteus y de ll años (C. I.: 90), según el de Binet $y$, en cuanto al segundo. quz demostró la exis. tencia de inteligancia $y$ reacciones psiquicas normales, sin apreciarse desviaciones dil instinto sexual.

Ante el resultado de los exámenes anteriores, sobre todo la relativamente alta cifra de eliminación de 17-ketosteroides $y$ negatividad, si pudiera decirse, de los exámenes dirigidus a investigar otras ctiologías, nos afirmamos en la hipótesis diagnóstica de ingreso de hallarnos en presencia de un cuadro de desarrollo sexual precoz, de origen cóticosuprarenal. Con el fin de confirmar esta esspecha, se practicó, por la ayuda que en algunos casos proforciona, pielcgrama intravenoso, examen que el especialista interpretó como negativo.

Ante tal situación, se estableció contacto con el Servicio de Urología del Prof. I. Díaz Muñoz, del Hospital del Salvador, en el cual el Dr. Luis Donoso tiene dilatada experiencia en el método de inyección de aire perirenal. De* bido, sin embargo, a oposición de la familia, no fué posible trasladarlo en esa oportunidad al establecimiento antes men cionado y debimos datlo de alta después de completar 8 dias de estadi en nuestro hospital-(18-VIII a' 26-VIII-45): . Fué sólo a comienzos del año en curso, en que el niño pudo ser hospitalizado en el Servicio de Urología del Salvador donde permaneció del 10-I al 5-II (Ficha No 46/442). El exa- 
men antes aludido permitió comprobar un aumento apreciable de la cápsula suprarenal izquierda (rad. 4), no así de la derecha, la cual, si bien la inyección de aire a este lado no fué muy satisfactoria, parecía estar de tamaño normal.

Dado el resultado del último examen, se decidió la in ${ }^{*}$ tervención operatoria, conducta que se adoptó en aterición a que desconocíamos la naturaleza de la tumoración. Si bien la evolución de cuatro años del cuadro hacía poco probable la existencia de una neoplasia maligna, la posibilidad de que llegara a tratarse de un adenoma, exigía la operación. Goldzieher, tal vez la mayor autoridad en clinica de cápsula suprarenal, expresa que tumores de esta glándula deben extíparse quirúrgicamente, tan pronto se diagnostican, debido a su probable malignidad, y que aun tumores benignos presentan esta indicación con carácter de absoluto, por su inherente potencialidad a la degeneración maligna.

El niño fué operado el 19 de abril en el Servicio de Cirugía del Hospital Luis Calvo Mackenna, por los Dres. Carlos Urrutia, Helmut Jaeger y Sebastián Narváez. Tal como indicaba el pneumcentgenograma perirenal, se encontró la cápsula suprarenal izquierda muy aumentada de tamaño, de 4 a 5 veces sus dimensiones normales para la edad del paciente. la que se extrajo. El postoperatrio transcurrio sin alternativas dignas de mención y el niño se dió de alta en buenas condiciones, a jos 12 días, con la indicación de seguir control periódico en policlínica. El examen bistopatológico de la pieza operatoria reveló la existencía de una gran hiperplasia de la sustancia cortical de la suprarenal. Informe: "Se exat mina una cápsula suprarenal extirpada quirúrgicamente. Pesa exactamente 15 grs.; mide $7 \mathrm{cms}$. de longitud por $27 \mathrm{mms}$. de ancho y $18 \mathrm{mms}$. de grosor. En general, conserva la forma de la suprarenal normal, siendo más alargada: la superficie presenta surcos que semejan la superficie cerebral. El examen histológico muestra exclusivamente tejido stxprarenal, notándose una marcada hiperplasia de la sustancia cortical. La sustancia medular conserva sús caracteres normales y hace contraste con la cortical, porque no participa del fenómeno hiperplásico. Las diferentes capas celulares muestran sus elementos en forma. tamaño y disposición absolutamente normal. En la cortical se encuentra una que otra: pequeña zona hemorrágica. Conciusión: hiperplasia de la dápyofula suprarenal a expensas de la sustancia cortical. Dr. A. Vargas". (Fotografía 3 y microfotografías 1 y 2 ). 
Por estimarlo de interés, dada la poca frecuencia con que se interviene en cápsula suptarenal, damos a continuación un resumen de técnicas de esta operación.

Las vías de abordaje de las cápsulas suprarenales son tres: 1. Vía anterior o transperitoneal. 2. Vía antetior paraperitoneal de Bazy, y 3. Vía posterior o lumbar de Hertz. La primera, que ha sido la más usada en otros tiempos, tiene muchas"variaciones, según se deje el colon por fuera, a, lo que es mejor si se bace el despegamiento parietal y se desplaza hacia la línea media. Sus inconvenientes principales derivan del shock operatorio, profundidad en que se actúa y gtan vascularización de la zona, por encontrarse en ella la cola del páncreas. La via paraperitoneal. difundida por Bazy, se sigue mediante una incisión trancversal, con el enfermo en decúbito dorsal y cojín en la región lumbar. en forma semejante a la oferación de vesícula. Se secciona transversalmente $1 \mathrm{a}$ extremidad de la $11^{\text {t }}$ costilla. Tiene como peligros o inconvenientes la lesión de la musculatura por la amplitud de la incisión y la vecindad de la pleura. La vía posterior o lumbar, que fué la que se eligió en este paciente, corresponde a la técnica de Hertz, cuyos cuatro tiempos principales van demostrados en los gráficos.

Fig. 1: Pcsición del enfermo e incisión a lo largo de la $12^{3}$ costilla.

Fig. 2: Se va en busca de la costilla, que se desperiostiza y reseca; inmediatamente por debajo de la costilla resecada se incinde la aponeurosis del transverso, evitando abrir la pleura y el peritoneo. "En la región posterior es donde liay mayores garantías de evitar estes órganos.

Fig. 3: Queda, así, el peritoneo visible y diferenciable hacia adelante $y$, en la parte posterior, la celda renal. Se llega, entonces, al polo superior del riñón, sobre el cual y. un poco hacia la línea media, está la cápsula.

Fig. 4: Disección de la cápsula: extracción o disección del tumor. Es de hacer notar que para extraer las cápsulas suprarenales, se hace necesario ligar varios pedículos, espe. cialmente en la parte inferior y posterior, como se ve en los esquemas de esta figura.

\section{CASO $\mathrm{N}^{+} 2$.}

Ceciliz M. - Gbservación clinica: 45/2841. - Edad: 10 años 9 meses.

Enfermedad actual. - Es traida a consulta (19-V.45) por su madre. por presentar, desde bace años, cirtas anomalias fisicas y funcionales. Sey̆in declarzción de ésia, la rifáa menstruó por primeta vez a los cinco átios, ed at 
desce la cual sus periodos se han sucedido con relativa regulatidad, cada 28 a 30 días. Ellos se caracterizan por ser abundantes, de 8 a 10 días de duración. y acompañarse de escasas molestias genetalis. A partir de la fecha de instalación de $1_{\AA}$ menstruación, se empezaron a nocar en la niña algunos cambios. entre ellos, marcado crecimiento longitudinal, aparición de vello púbico $y$ asilar y moderado desartollo di los senos.

Autecedentes familiates. - Padre de 30 años, madre de 27. aparenternentz sanos. En ambos, fa reacción de Kahn. hecha recientemente, ha 'sido negativa. Hasca hace a año convivió con ellos ua adulto con tuberculosis pallmonar, que falleció. Padre, bebedor ocasional. Seis hijos, 2 fallecidos de bruna coneumoria en la primera infancia: tistantes vivos, aparentemente sanos. No ha babido abortos. La investigación sobre desarrollo sexulal precoz a otras anomatias fisicas o funciones en miembros de la familia, es regativa.

Antecedenteq personales. - Nació de embatazo de térnino, en parto eeltócico, atendido en el Hospital Sar Borja. Pesó 3.500 grs. Fné alimentada a) pecho materno exclusivo hasta los 7 meșes, edad a la cual se agregaron stpas, purés y jugos de frutas, para siguir posteriormance con burvo e bígado. A partir del à̃o, alimentación completa. Se dice baber tenido buen desarrollo pondoestarural durante la primera infancia. A los 3 meses, apatición de los inciścios centräles inferiores: crupción regular de los siguientes. Sostuvo la ca. beza a los 3 meses, se sencó a los 6 y anduvo al aila. Primeras palabras a los 10 meszs. A los 4 arios coqueluche y bronconellmonia.

\section{Examen objetivo.}

Fosición actifa. Deambulación normal. Psiquis lúcido. Piel morena, sana. Se palfan numerosos ganglios submaxilares del tamaño de un poroto. Bun estado nutritivo. Paniculo adiposo, en rigular cantidad, localizado de preférencia en la pared abóomizal, cintura pelpiana y mitad superior de los muslos y brazos. Senos prominentes. Areola intensamente pigmentada, con fezones bien desarollados. A nival d: los genitales extetnos y region pubiana ó aptecia morerado desarrollo de vello, de distribución femenina; tambión, si bien escaso. en las axilas. Discreto bozo (fotografías 4 y 5 ).

Peso: 39.5 kgrs.; talla: 140.5 cms.: đesuiación por ciento del peso del standard de peso fara talla y edad: +12.8\%; circunferencia del cráneo: 55 cms.; circunferencia del tórax: $72 \mathrm{kms}$; circunferencia del abdomen: $70 \mathrm{cms}$; segmento superior: 74.5 cms.: sigmento inferior: 66 cms., $y$ envergadura: $1.40 \mathrm{~cm}$.

Pulso: 80; respiraciones: 19 ; temperatara: $36.8^{\circ}$; presión sanguínea: $114 / 66$.

Cabeza. Cráneo: nada de especial; boca: mucosas húmedas, sanas, dentadura completa. bien implantada, con caries avanzadas of molates; faringe: ligiramente entojicida; tonsilas: de tamaño normal; ojos: reacciones a la luz y 
accmodación normales: visión: O. D. 5/10, O. I, 5/5 parcial: fondos: papila rosada, plana, de bordes nitidos: vasos: de buen aspecto: cruces arterioveпоксал: negativos; mácula: sana; cuzllo y tórax: nada de especial; abdomen: ligiraminte frominente, de paredes firmes, indoloro; higado: se palpa su límite inferior en el reborde costal; bazo: se percute dz tamaño normal; no se falpar masas; genitales: desarrollo de tipo adulto de los labios mayores y menores: clitotis: d tamaño normal; sxtremidadas; nada de eipecial.

Ante las carncteristicas del fuadro clinico y su evolución. s? plantean como los diagnósticos ctiológicos de mayor probibilidad, los de desarrollo sexual precoz da origen idiopático u ovático, en sute último caso, tumor de células granulosas. y a fin de hacer posible ha realización de los exámenés tendientes a avanzar en estc estudio, la rit̄ía se hospitaliza. Durante la permanencia di ésta in el hospiral (23 a 29-VIII-45), st practicaron los exámeneg que J continuación se detallan: Pirquet: + : radioscopía de tórax normal; KabnKline y orina: nrgativos: colesterolemia: 1.1 gr. por mil; hemogtama: glóbrlus rojos: $4.020,000$ : glóbulos blancos: 9.900 ; hemoglobina: 13.5 ; basófilos: 0: eosinćfilos: 2; mielocitos: 0 ; juveniles: 0 ; baciliformes: 2; segmenados: 52: linfocitos: 40, y monocitos: 6; pruaba de tolirancia a la glucosa: 1.14, 1.53, 1.28, 1.08 y 0.66 gr, for mil: capacidad vital: $-9 \%(2,260$ c.c., 1.81 c.c. $x$ m.2); creatinina y creatina en orina de 24 hocas: 624 y 76 mgts, tespectivämentio (coeficieates $\mathrm{d} \geq \mathbf{1 5 . 7}$ y $1.8 \mathrm{mg} / \mathrm{kg}$ ): metabolismo basal: $+6.2 \%$; acción dinamica especifica d2 las proteinas: $+5.9 \%$; campos visuales: ncrmales: radiografía dz cráneo (rad. 4); neumatización y silla turca normal (silla turca: daberia cener 1.2 y 0.62 cms, ci ne 1.1 x 0.70 ): radiografía de catpo (tad. 5): edad ösea de i5 años: 17-ketosteroides urinarios: $6.7 \mathrm{mg}$ de androsterona en 74 horas $y$ estrógenos utinarios: 32 unidades rata de estrena en 24 horas.

Postericrmente se practicó exploración de los genitales por tacto rectal. previo lavado intestinal, la cual, según los especialistas que examiraron, Dres. H. Jirón y R. Brañes, no reveló, fuera de discreta desviación del útero hacia la derecha, nada de especial. Dado que el resultado de este examen en forma alguna podía cons derarse argumento suficiente para excluir la existencia de un tumor de células granulosas. Jos que, en ocasiones, como Hoffman lo hace presente, son tan pequeños, que aun con los genitales ante la vista pueden pasar desapercibidos, se propuso a la familia, sin que ésta lo aceptara. la hospitalización de nuevo de la niña, con el objeto de practicar otros exámenes. Ya que por dificultades técnicas no habría sido posible conseguir. a la fecha, entre nesctros, determinaciones de pregnanediol, pensamos que frctis vaginales repetidos y la biofsia endometrial podrian habernos dado luz en la dilucidación eticlógica de este caso. 
Como antes se dijo, niñas con precocidad de origen idiopático, presentan cvulación. lo que no ocurte en aquéllas en que el cuadro es consecutivo a causa ovárica.

\section{Comentario.}

Los casos antes descritos dan pie para consíderaciones de importancia. En ambos es de resaltar, especialmente en el primero, la valiosa ayuda que exámenes auxiliares proporcionaron en el estudio de los pacientes. Ya anteriormente hicimos presente las dificultades que a menudo comporta al diagnóstico exacto en este tipo de enfermos. y el cual, en no raras ocasiones. sólo puede asegurarse en la intervención a examen histopatológico.

En la primera observación, la del niño, por ejemplo, la clinica, si bien nos proporcionó una orientación útil, no pudo llevarnos a la precisión diagnóstica. Al pasat revista a las posibilidades que debimos considerar, al tratar del probable origen del cuadro, en este caso, debemos decir que desde un comienzo eliminamos los testículos. Tanto el examen físico, que comprobó glándulas descendidas, de tamaño, forma y consistencia normal, como la evolución de cuatro años del síndrome, nos inclinaron en tal sentido. Cuando él teconoce como etiología tumores testiculares, éstos, como antes se dijo, se desarrollan en la mayor parte de los casos en testículos ectópicos, sin contar que, debido al alto porcentaje en que tienen carácter maligno. su crecimiento es rápido y la pro. ducción de metástasis precoz.

Pasamos, en seguida, a analizar el crigen pineal, hipo fisiario y cerebral. Estimamos del caso colocar aqui juntas estas tres etiologias, en atención al gran parecido de las características fisicas que en ellas reviste el cuadro de desariollo sexual precoz, así como a la semejanza de algunos de los signos y sintomas que delatan dicho compromiso. La in Vestigación en este sentido dió, en nuestro paciente, resultados negativos. En efecto, ni la radiografía de cráneo reveló datos de impcrtancia ni tampoco los exámenes clínicos, neurológico, de fondo de ojo y campos visuales. Esto merece ser destacado, ya que ante la evolución de 4 años del cuadro. tendía a hacer altamente improbable las etiolcgías antes mer. cionadas como causa del síndrome. En cuanto a la hiperneumatización del cráneo y al aumento de la acción dinámica específica de las proténas. en ausencia de alteraciones de la silla turca u otros signos de comprcmiso hipofisiario, daci- 
aimcs sólo anctarlas, en especial después de la declaración de Le Marquand y otros, de que es dodeso de que la hipotesis func.cne normalmente en pacientes ecn cuadros de precocidad sexual de origen córticosuprarenal.

Sólo restaban, entonces, como posibilidades finales, los oríganes córticosuprarenal e idiopático o constitucional, a pesar, este último, de la falta de antecedentes familiares. Debemos declarat, como ya lo hicimos presente, que desde un comienzo, impresionados por el fuerte desarrollo muscular del paciente, sospechamos la eticlogía córticosuprarenal, no obstante no existir obesidad ni hirsutismo. Era tan manifiesta, en realidad, dicha característica, que al término del primer examen, dimos los pasos necesarios para precisar el estado $y$ función de las suprarenales. Se practicó, así, la determinación de los 17-ketosteroides, hcirmona, como se sabe, de propiedades androgénicas y de la cual se conocen las fracciones alfa y beta. Es producida tanto por los testículos como corteza ruprarenal y en forma tal que mientras los ketosteroides alfa se generan en ambos sitios, si bien principalmente en los primeros. los beta son un producto exclusivo de las suptarenales Es así posible, entonces, a partir de la determinación de esta sustancias en la orina, conocer, en comparación con las cantidades normales de excreción de ellas, el estudo funcional de las glándulas mencionadas. En nuectro caso. si bien por dificultades técnicas, no fué posible realizar el análisis separado de las dos fracciones de ketesteroides, la comprobación de una cifra elevada, 18.4 mgrs. en 24 horas (normal en este caso de 4 a 6 mgrs.), indicaba, ante la $2 \mathrm{u}^{-}$ sencia de lesión testicular. la existencia de un compromiso de la corteza suprarenal.

Ante el resultado del examen anterior, sólo restaba, de set posible, precisar cbjetivamente la lesión. A este efecto se practicó pielograma intravenoso, el cual, si bien casi siem. pre sólo en casos de tumores extensos ofrece información. hay cbservaciones de simples hiperplasias. confirmadas a la cperación, en que ha sido útil. En nuestro caso, el radiólogo informó no apreciar anormalidades en la forma, tamaño ni posición de los riñones. Én vista de este resultado se hizo pneumoroentgenograma perirenal, el cual confirmó, al revelar un aumento apreciable de la cápsula suprarenal izquiérda, el diagnóstico de probabilidad -altetación córticosuprarenal- sentado en un comienzo.

Un punto que merece explicación es el relativo al peso del paciente. Podría. quizás, decirse, desde que el niño pre- 
sentaba una desviación percentual del peso de $+27 \%$, según el standard nacional de peso para talla y edad, que él era obeso, afirmación que tanto la clínica como el coeficiente de creatinina ( 27.8 mgrs. $/ \mathrm{kgr}$.) demuestran que no es exacta. En efecto, no basta, como se sabe, que un sujeto tenga un peso que excede los limites superiores del margen normal de desviación del peso que le corresponde de acuerdo con su talla y edad. para formular tal diagnóstico, sino que dicho sobrepéso debe estar ccnstituído, como por definición se comprende, por tejido adiposo. En este caso. la simple observación indicaba que el excesivo desarrollo muscular tenía que responder del hecho antes anctado, deducción que confirmó el cceficiente de creatinina. Este mismo significado se ha de conceder igualmente, lo que consta en trabajos de diferentes autores, a la comprobación de un alto valor de capacidad vital.

En cuanto al segundo caso, debíamos sentar también un diagnóstico etiológico. Las posibilidades aquí se reducían, ya que la etiología suprarenal podia excluirse. En el cuadro, désido a compromiso córticosuprarenal, no existe, en efecto, menstruación ni tampoco desarrollo de las glándulas mamarias y, además, tiene en él la característica de una manifestación sobresaliente la presencia de hirsutismo. Otra razón que igualmente dejaba fuera de consideración la etiología suprarenal en esta niña era la ausencia de crecimiento anormal del clítoris que en tal caso siempre se halla. En apoyo de todo lo anterior, podíamos, finalmente, citar la determinación de los 17-ketosteroides, que reveló cantidades de eliminación normales de esta hormona.

Las etiologías pineal, hipofisiaria y cerebral tamporo tenían, en nuestra opinión, posibilidades. Sin contar que, según muchos autores, la primera de éstas sólo ba sido telarada hasta ahora en varones, la evolución do casi 6 años del cuadro, en ausencia de signcs y sintomas de lesión intracraneana y exámenes de fondo de cjo. campos visuales y radiográfico negativos, bacían difícilmente sostenible cualesquie. ra de dichas etiologías.

No quedaban, entonces, sino dos probables origenes del cuadro en este caso, el idicpático o constitucional y el ovárico. Dado que de tratarse la primera etiología, que según Seckel alcanza una frecuencia más alta que todas las restantes juntas, no sería dable encontrar, fuera de la sintcmatología propia del cuadro, otros datos positivos, dirigimos nuestra investigación en el sentido de la segunda posibilidad. Fué 
así cómo se practicó tacto rectal, para exploración de los ovarios, $y$ determinación de estrógenos urinarios. $\mathrm{El}$ resultado negativo del primer examen, en ningún caso excluye, como ya se dijo, la existencia de un tumor de células granulosas, las dimensiones del cual scn, a veces, tan pequeñas, que resultan difícilmente distinguibles a simple vista. Igual significado se ha de conceder a la excreción urinaria de estrógenos, cuya cifra - correspondiente a la de mujer adulta normal-, - si bien es baja en relación a la encontrada en la mayoría de les casos de tumor de células granulosas, es posible también hallarla en ellos.

Ante la situación de duda diagnóstica recién señalada. estimamos que significaría una ayuda considerable la realización de exámenes tendiente a determinar si existe o no ovulación $€ n$ esta niña, sabido que en pacientes con tumor del tipo del antes mencionado. los períodos menstruales no son ovulatcrios. Dado que desgraciadamente, como ya se dijo, esto no fué factible, el diagnóstico etiológico en este caso, en la impcsibilidad de excluir totalmente el origen ovárico, queda, en consecuencia, indeterminado.

En los dos cascs antes descritos, existe, como se rió, una avanzada edad ósea, sobre la cual no nos vamos a extender, ya que es un signo que se presenta en cualquier paciente de este tipo, sea cual fuere su etiología, como reflejo del efecto de las hormonas sexuales sobre el esqueleto. Igual explicación tienen - acción de las hormonas antes mencionadaslas cifras de aliminación de creatina observada en ambos casos $(0.2 \mathrm{mgr} / \mathrm{kgt}$. en el niño y 1.8 en la niña). Por último, las medidas antropométricas. que revelan una manifirsta desproporción entre los segmentos superior e inferior, en desmedro de este último, nuevamente son consecuencia de la intervención de las hormonas sexuales que después de producir una aceleración del crecimiento, conducen a una detención de éste, con los resultados antes mencicnados, debido a solda- , dura precoz de las líneas epifisiarias de crecimiento.

\section{Resumen.}

Se relatan dos casos de decarrollo sexual precoz, atendidos últimamente en el Hospital Luis Calvo Mackenna. Uno de ellos, un niño de 12 años, presentaba el cuadro desde los 8. y el otro, una niña de 11, desde los 5. En el primero, el rindrome se caracterizabi por pene grande, existencia de vello púbicc y axilar, marcado desarrollo muscular y voz 
gruéa, y en el segundc, por menstruación, desarrollo de los cenos y vello púbico y axilar. En ambos existía un estado zvanzado de osificación del esqueleto, con casi soldadura, en ₹I niño, de las líneas epifisiarias de crecimiento.

En el primer caso, el estudio de los signos y síntomas del paciente, unido al resultado de algunos exámenes especciales, entre ellos. determinación de 17 -ketestetoides y pneumoroentgenograma perirenal, permitieron sentar el diagnís-. tico etiologice de hiperinterrenalismo, el que se confirmó en la operación (gran hiperplasia cortical de la cápsula suprarenal izquierdá). En cuanto a la niña, en atención a que no ha sido pcsible realizar los exámenes tendientes a determinar si existe o no ovulación, el diagnóstico causal no es seguro y ascila, en opinión de los autores, entre los orígenes idiopático y ovárico (tumor de células granulosas).

Se revisa la etiopatogenia y diạgnóstico diferencial de los estados de desarrollo sexual precoz.

\section{Sunomary.}

Two cases of precocious sexual development recently seen at the Luis Calvo Mackenna Children's Hospital are reported. In one of them, a boy of 12 years of age, the clinical picture had appeared at the age of 8 , and in the other one, a girl aged 11 years, when she was 5 years old. In the first patient the syndrome was characterized by enlargement of the penis, growth of pubic and axillary hair, marked muscular development and deep voice and in the second one by menstruation, enlargement of the breasts and growth of pubic and axillary hair. In both children there was an acceleration of their bone development, with almost closure, in the boy, of the epiphyseal lines.

In the boy an analysis of his signs and symptoms coupled with the results of several diagnostic aids, particularly assay of 17 ketosteroids and perirenal insufflation, permitted to establish the etiological diagnosis of hyperinterrenalism, which was confirmed at operation (marked cortical hyperplasia of the left adrenal gland). As regards the girl, due to the fact that methods to ascertain whether there is or not ovulation have not thus far been employed, the final diagnosis is not yet settled and it probably remains, according to the author's view, between the idiopathic and ovarian (granulosa cell tumor) origins. 
The ctiopathogenesis and differential diagnosis of this syndrome are reviewed.

Deseamos expresar ruestros agradecimientos a los Drzs. Luis Donoso y Atturo Yáncz, po: su cooperación en ta realización de a!gunos exámenes.

\section{Bibliografía.}

BRONSTEL, I. - Hypergenitalism. \&. Pediat. 14: 203-212, febrero de 1939.

BRONSTEJN, I, LUHAN, J. y MAVRELIS. W. - Sexual precoity associated with hypexplastic abnormality of tuber inereum. Am. J. Dis. Chi!d. 64: 211-220, agosto de 1942 .

BRUCH, H. - Obssity in relation to puberiy. J. Pediat. 19:365+375, setiembre d: $194 \mathrm{~L}$.

CORREA, O. - EI standard de cratinina en la predicción del metabolismo bas::I. Rew. Ch. de Pediat. 15: 360-371, mayo d2 1944.

FARBER, J.: GUSTINA, F. y POSTOLOFF, A. - Cushing's syndrome in childten. Am. J. Dis. Child. 65: 593.603, abril de 1943.

FRRNK, R. - Sex-endocrine factors in bloot and urine in health and diseas: I. A. M. A. 104: 1991-1993, $1^{\circ}$ de junio de 1935 .

FRASER. I. - Pricocious pubercy in boy: of one year. Brit. J. Surg. 27 : 521-526, snero de 1940 .

GoldzleHER. M. - The endocine glands. New York, Appleton Century, 1939.

HOFFMAN, J. -- Female endocrinology intuding sections on the male. Psi[ade]phia. Saunders, 1944.

ILLANES, O y CORREA, O - Estudios de capacidad vital en escolares tiormates. Rev. Ch. de Pediar. 15: 815.829, actubre de 1944.

KARNAKY, K, -- Prematurz sexual precocity in a young girl. J. Clin. En-1 decrinclogy. 5: 184-188, abril de 1945

NATHANSON. I. y AUB, J. - Exeretion of sex hormone in abnormalities of puberty. J. Clin. Endocrinology. 3: 321-330, junio de 1943

CLEA, R. - Hipotiroidismo a hiperovarismo. Arth. Hosp. Roberto del Río. 10: 186-193, diciembre de 3941 .

RASCOVSKY, A.; SALZMAN, J.: GAGLIARDI, J. y TALLAFERRO, S.

- - Estudio comparativo de los elementos de maduración que acompañar a un cuadro de macrogenitosomia precot. y a uno de enarismo con hipogenitalismo. Arch. Argent. de Pediat. 15: 243.252. marzo de 1941 .

ROWNTREE, L.; CI.ARK, J.; STEINBERG. A. \& HANSON, A. - Biclogic effects of pineal extract (Hanson). J. A. M. A. 1065370.373, $1^{\circ}$ de febrero de 1936

SECKEL, H. - Precocious sexual development in thildren. Medical Chinics of North Anerica. Philadelphia. Sanders, 1946. 
SCHACHTER, M. - La macrogenitosoria precoz (o pubertad precoz) de origen cerebral (Formas "dizncefálicas" o "hipotalámicas"). Rev. Clín. Españ. 7: 324-328, 15 de diciembre de 1942.

SHORR, E. - Endocrine problems in adolescence. J, Pediat. 19: $327 \cdot 346$. setiembre de 1941.

STERNBERG, W. Y JOSEPH, V. - Osteodystrophia fibrosa combined with precocious puberty and exoftalmic goiter. Am. J. Dis. Child, 63: 748. 783, abril de 1942.

TALBOT, N. y BROUGHTON. F. - The measument of obesity by srestinine coefficient. Am. J. Dis. Child. 55: 42-50, enero de 1938.

TALBOT, N.; BUTLER, A. y MACLACHLAN, E. - Alpha and beta neutrai kecosteroids (androgens). New England J. of Medicinc. 223: 369-373, setiembre de 1943 .

THELANDER, H. y CHOLFFIN, M. - Neonatal cottical insufficiency (Addison's disease) associatid with adtenogenital syndrome. 5. Pediat 18 : 779-792, junio de 1941.

VIAMONTE, L. - Macrogenitosomia precoz con oligofrenia. Bol. Soc. Cubana de Pediat, 12:181.202. mayo de 1940.

WEINBERGER. L. y GRANT, F, - Frecocions puberty and tumors of hypothalamus. Areb. Int. Med. 67: 762-792, abril de 1941.

WERNER. A. - Endocrinology. Clinical applisation and treatment. Philadelphia, Lea ad Febiger, 1942.

WILKINS, L.; FLEISHMANN, w, y HOWARD. J. - Macrogenicosomia praecox associated with hyperplasia of androgenic tissue of adrenal and death from cortico-adrenal insufficiency. Endocrinology. 26: 385-395. marzo de 1940.

WINTERSTEINER, O. - The adrenogenital syndrome: Glandular Physiology and Therapy, Chiçago, American Medical Association. 1942.

ZONDEK. H. - Diseases of the endocrine glands. Baltimore. William. Wood and Co., 19?6. 